\title{
horticultura
brasileira
}

LOPES, WAR; NEGREIROS, MZ; RESENDE, FV; LUCENA, RRM; SOARES, AM; SILVA, OMP; MEDEIROS, JF. 2016. Produção de alho submetido a períodos de vernalização e épocas de plantio em região de clima semiárido. Horticultura Brasileira 34: 249-256. DOI - http://dx.doi.org/10.1590/ S0102-053620160000200016

\section{Produção de alho submetido a períodos de vernalização e épocas de plantio em região de clima semiárido}

\author{
Welder AR Lopes ${ }^{1}$; Maria Z Negreiros ${ }^{1}$; Francisco V Resende ${ }^{2}$; Rafaella RM Lucena ${ }^{1}$; Alinne M Soares ${ }^{1}$; \\ Otaciana MP Silva ${ }^{1}$; José F Medeiros ${ }^{1}$ \\ ${ }^{1}$ Universidade Federal Rural do Semi-árido (UFERSA), Mossoró-RN, Brasil; welder.lopes@hotmail.com; zuleide@ufersa.edu.br; \\ rafaellarayane@hotmail.com; alinne_menezes@hotmail.com; otaciana_silva@yahoo.com.br; jfmedeir@ufersa.edu.br; ${ }^{2} E m b r a p a$ \\ Hortaliças, Brasília-DF, Brasil; francisco.resende@embrapa.br
}

\section{RESUMO}

Com o objetivo de avaliar a produção de alho nobre submetido a períodos de vernalização e épocas de plantio, realizou-se um experimento em Baraúna-RN, de maio a outubro de 2012. Os tratamentos foram dispostos no esquema de parcelas subdivididas, delineamento experimental de blocos casualizados completos, com três repetições. Nas parcelas foram alocadas as épocas de plantio ( 22 de maio, 5 de junho e 23 de junho), e nas subparcelas os períodos de vernalização pré-plantio do alho-semente $\left(4 \pm 1^{\circ} \mathrm{C}\right.$ durante $50,55,60,65$ e 70 dias $)$. Foram avaliados comprimento de plantas, número de folhas, ciclo, estande final, massa média de bulbos, percentagem de plantas com bulbos, produtividade total de bulbos, classificação dos bulbos, número de bulbilhos por bulbo e classificação dos bulbilhos. O plantio em 22 de maio proporcionou maiores comprimento de plantas, número de folhas, estande final e massa média de bulbos; o ciclo decresceu com o tempo de vernalização; houve formação de bulbos com diferenciação de bulbilhos em todos os tratamentos sem, entretanto, haver ocorrência de plantas com superbrotamento; a produtividade total de bulbos aumentou com o tempo de vernalização de até 63 dias nos plantios em 22 de maio e 23 de junho, com médias de 5,20 e 3,85 t/ha; a combinação entre o plantio em 22 de maio e 65 dias de vernalização, foi a que proporcionou maior número de bulbilhos por bulbo e maior percentual de bulbos comerciais, distribuídos nas classes 3, 4 e 5. Esses resultados evidenciam ser possível o cultivo de alho nobre na região de Mossoró-RN utilizando o processo de frigorificação do alho-planta.

Palavras-chave: Allium sativum, frigorificação, superbrotamento.

\section{ABSTRACT}

Garlic production depending on vernalization periods and planting times in semiarid climate region

In order to evaluate the production of noble garlic under vernalization periods and planting times, an experiment was carried out in Baraúna, Rio Grande do Norte State, Brazil, between May and October 2012. Treatments were arranged in a split-plot in randomized complete block experimental design with three replications. The planting dates (May 22, June 5 and June 23) were allocated in the plots, and the periods of vernalization of the bulblets $\left(4 \pm 1^{\circ} \mathrm{C}\right.$ during $50,55,60,65$ and 70 days) in the subplot. Plant length, number of leaves, cycle, final stand, average bulb weight, percentage of plants with bulbs, total yield, classification of bulbs, number of bulblets per bulb and classification of bulblets were evaluated. Planting on May 22 provided higher plant length, number of leaves, final stand and bulbs mean mass; cycle decreased by vernalization time; there was formation of bulbs with bulblets differentiation in all treatments without occurring plant shoot proliferation; total yield of bulbs increased with vernalization time up to 63 days in plantations carried out on May 22 and June 23, with averages of 5.20 and $3.85 \mathrm{t} / \mathrm{ha}$; the combination of planting on May 22 and 65 days of vernalization provided greater number of bulblets per bulb and higher percentage of marketable bulbs, distributed in classes 3, 4 and 5. These results show the possibility of noble garlic production in the Mossoro region, using the refrigeration process for bulblets.

Keywords: Allium sativum, cold storage, oversprouting.

(Recebido para publicação em 10 de junho de 2014; aceito em 31 de agosto de 2015) (Received on June 10, 2014; accepted on August 31, 2015)

$\mathrm{N}$ o Brasil, pesquisas com a cultura do alho têm aumentado nos últimos anos, resultando em incrementos de produtividade, entre as quais, pode-se destacar o uso de cultivares mais adaptadas para o plantio em diversas regiões produtoras, vernalização de alhos nobres (Souza \& Macêdo, 2004; Fiorese \& Viecelli, 2009; Resende et al.,
2011), manejo da adubação (Trani et al., 2008; Macêdo et al., 2011; Souza et al., 2011) e irrigação (Macêdo et al., 2006), ponto de colheita ideal e armazenamento adequado (Oliveira et al., 2004), entre outros.

As exigências do alho com relação ao fotoperíodo e à temperatura são alguns dos fatores que mais condicio- nam a escolha da época de cultivo. As cultivares existentes diferem entre si quanto às exigências ao fotoperíodo e temperatura, permitindo assim certa flexibilidade quanto à época de plantio (Souza \& Macêdo, 2009).

Nos últimos anos, a adoção da prática de vernalização possibilitou o plantio de cultivares de alho nobre em regiões 
onde as condições termo-fotoperiódicas não satisfazem as exigências da planta (Macêdo et al., 2009, 2011), como nas regiões do centro-oeste e nordeste brasileiro. As cultivares de alho nobre são aquelas que têm ciclo substancialmente mais longo, sendo de seis meses ou superior, além disso, são mais exigentes em fotoperíodo (mínimo de 13 horas) e temperaturas amenas. Somente podem ser plantadas em regiões com condições climáticas diferentes das exigidas aplicando-se a técnica da vernalização (Souza \& Macêdo, 2009).

A técnica consiste em armazenar o alho-semente em câmara com temperatura de 3 a $5^{\circ} \mathrm{C}$, por um período de 40-60 dias, com umidade relativa do ar entre 70 e $80 \%$, devendo ser retirado da câmara à véspera do plantio, pois a permanência desses fora da câmara, por um longo período, pode resultar na desvernalização, afetando a bulbificação (Souza \& Macêdo, 2009).

Em Lavras-MG, Pereira \& Souza (2002), trabalhando com períodos de vernalização nas cultivares Roxo Pérola de Caçador e Gravatá, verificaram que a vernalização promoveu o aumento na altura média de plantas, número de folhas vivas e de plantas emergidas, e diminuição no ciclo vegetativo para ambas as cultivares. Para a cultivar Roxo Pérola de Caçador, o melhor período de vernalização foi de 60 dias a $4^{\circ} \mathrm{C}$, obtendo produtividade comercial de $6,6 \mathrm{t} / \mathrm{ha}$.

Os efeitos dos períodos de frigorificação, a 15 e $4^{\circ} \mathrm{C}$, na superação da dormência, na vernalização e na produtividade de alho da cultivar Roxo Pérola de Caçador foram estudados por Reghin \& Kimoto (1998). Para planejamento do plantio em abril, em Botucatu-SP, foram recomendados períodos mais curtos de frigorificação, com dez dias de pré-vernalização a $15^{\circ} \mathrm{C}$, seguidos de quarenta dias de vernalização a $4^{\circ} \mathrm{C}$, realizado imediatamente antes do plantio. Os autores afirmam que para a cultivar estudada, a vernalização a $4^{\circ} \mathrm{C}$ pode substituir plenamente a exigência em fotoperíodos mais longos. Além disso, observaram que prolongando o tratamento de 30 para 60 dias de vernalização a $4^{\circ} \mathrm{C}$, a época de diferenciação diminuiu de 60 para 43 dias, e consequentemente, promoveu uma colheita mais precoce, sem reduções significativas na produtividade, com produtividade média de 12,9 t/ha entre todos os tratamentos.

Apesar da utilização da técnica de vernalização em pré-plantio ter possibilitado a produção de alho nobre em regiões onde as condições de temperatura e fotoperíodo naturalmente não satisfazem as exigências da cultura, verifica-se, que as cultivares não têm respostas similares à vernalização (Fiorese \& Viecelli, 2009). Resende et al. (2011), avaliando duas cultivares submetidas a três períodos de vernalização (30, 40 e 50 dias) e três épocas de plantio $(23 / 03,23 / 04$ e 23/05) verificaram que houve aumento da emergência e altura média de plantas na primeira época de cultivo, com maior padrão comercial nas duas primeiras épocas para a cultivar Quitéria e na segunda época para a cultivar Caçador. O período de 40 dias de vernalização foi o que permitiu às cultivares melhor complementação às condições de fotoperíodo e temperatura do ambiente de cultivo, proporcionando desenvolvimento vegetativo e produção satisfatórios na região de Guarapuava-PR.

Objetivou-se com o presente trabalho, avaliar o efeito de períodos de vernalização e épocas de plantio na produtividade do alho cv. Roxo Pérola de Caçador em Baraúna-RN.

\section{MATERIAL E MÉTODOS}

O experimento foi conduzido entre maio e outubro de 2012 na Fazenda Santa Luzia, município de Baraúna-RN (5'5'50'S, 37³3'1'”, altitude de 120 $\mathrm{m})$. A região possui fotoperíodo com pouca variação, em torno de 12 horas, durante todo o ano. O clima da região, segundo classificação de Köppen, é do tipo BSwh', isto é, seco e muito quente, com duas estações climáticas: uma chuvosa que vai, geralmente, de fevereiro a maio e uma seca, de junho a janeiro. O município de Baraúna está localizado na Chapada do Apodi, microrregião de Mossoró-RN. Durante a condução do experimento, realizou-se o monitoramento climático da região, e observou-se temperaturas mínimas entre 19,2 e $25,3^{\circ} \mathrm{C}$, temperatura média de $27,7^{\circ} \mathrm{C}$ e máximas entre 30,0 e $36,9^{\circ} \mathrm{C}$. A umidade relativa média foi de 56,5, 55,2 e 54,2\%, durante o primeiro, segundo e terceiro cultivos, respectivamente.

O solo da área experimental é classificado como Cambissolo Háplico de textura média (Embrapa, 2013), cuja análise química apresentou as seguintes características: $\mathrm{pH} \mathrm{H}_{2} \mathrm{O}=5,8, \mathrm{P}=2,7 \mathrm{mg}$ / $\mathrm{dm}^{3}, \mathrm{~K}=216,0 \mathrm{mg} / \mathrm{dm}^{3}, \mathrm{Na}=5,8 \mathrm{mg} /$ $\mathrm{dm}^{3}, \mathrm{Ca}=4,69 \mathrm{cmol}_{\mathrm{c}} / \mathrm{dm}^{3}, \mathrm{Mg}=0,93$ $\mathrm{cmol}_{\mathrm{c}} / \mathrm{dm}^{3}, \mathrm{Al}=0,00 \mathrm{cmol}_{\mathrm{c}} / \mathrm{dm}^{3}$ e $\mathrm{MO}=$ $7,79 \mathrm{~g} / \mathrm{kg}$.

Os tratamentos foram dispostos em parcelas subdivididas, delineamento experimental de blocos casualizados completos, com três repetições. Nas parcelas foram alocadas as épocas de plantio: 22 de maio, 5 de junho e 23 de junho, e nas subparcelas os períodos de vernalização pré-plantio do alho-semente: 50, 55, 60, 65 e 70 dias.

Empregou-se a cultivar Roxo Pérola de Caçador. É uma cultivar de alho nobre, de ciclo tardio, com bulbos redondos e grandes, túnica de coloração branca, de sete a nove bulbilhos com película de cor rósea ou roxa (Resende et al., 2013).

Os bulbos-semente passaram pelo processo de vernalização em câmara frigorífica à temperatura de $4^{\circ} \mathrm{C} \pm 1^{\circ} \mathrm{C}$ e umidade relativa de $70 \%$. A entrada dos bulbos de cada tratamento na câmara frigorífica foi feita de modo que o plantio dos bulbilhos das subparcelas ocorressem na mesma data, conforme as épocas de plantio.

As subparcelas foram constituídas por canteiros de 0,2 $\mathrm{m}$ de altura, 1,0 m de largura e 2,0 m de comprimento, com cinco linhas de plantio. Os bulbilhos foram plantados a uma profundidade de $5 \mathrm{~cm}$, com espaçamento de $20 \mathrm{~cm}$ entre linhas e $10 \mathrm{~cm}$ entre plantas. A área útil de cada subparcela foi constituída pelas três fileiras centrais, descartando-se uma planta em cada extremidade das fileiras, resultando numa área de $1,08 \mathrm{~m}^{2}$ e 54 plantas úteis.

No preparo do solo realizou-se uma aração e uma gradagem, seguido do levantamento dos canteiros. Baseada na análise do solo, foi realizada a adubação de plantio com $30 \mathrm{~kg} /$ ha de $\mathrm{N}$ (sulfato de amônio), $60 \mathrm{~kg} /$ ha de $\mathrm{P}_{2} \mathrm{O}_{5}$ (superfosfato 
simples), $20 \mathrm{~kg} / \mathrm{ha}$ de $\mathrm{K}_{2} \mathrm{O}$ (cloreto de potássio), $15 \mathrm{~kg} / \mathrm{ha}$ de $\mathrm{Mg}$ (sulfato de magnésio), $7 \mathrm{~kg} / \mathrm{ha}$ de $\mathrm{Zn}$ (sulfato de zinco), $1,7 \mathrm{~kg} / \mathrm{ha}$ de $\mathrm{B}$ (ácido bórico) e $40 \mathrm{t} / \mathrm{ha}$ de Pole Fértil ${ }^{\circledR}$, à base de esterco bovino e de galinha decompostos, com $1 \%$ de $\mathrm{N}$ total, $15 \%$ de $\mathrm{C}$ orgânico, $50 \%$ de umidade, $\mathrm{pH}$ 6,0 e CTC de 80 $\mathrm{mmol} / \mathrm{dm}^{3}$.

As adubações de cobertura foram realizadas em duas aplicações, uma aos 30 dias após o plantio (DAP), com as fontes ureia $(30 \mathrm{~kg} / \mathrm{ha}$ de $\mathrm{N})$ e cloreto de potássio $\left(20 \mathrm{~kg} / \mathrm{ha}\right.$ de $\left.\mathrm{K}_{2} \mathrm{O}\right)$, e outra aos 60 dias utilizando ureia $(30 \mathrm{~kg} / \mathrm{ha}$ de $\mathrm{N})$.

Utilizou-se irrigação por microaspersão, com vazão de $27 \mathrm{~L} / \mathrm{h}$ para uma pressão de $200 \mathrm{KPa}$, sendo dois microaspersores por subparcela. A fim de monitorar a umidade do solo durante a condução do experimento, foram instalados tensiômetros a 15 e $30 \mathrm{~cm}$ de profundidade.

Devido à suscetibilidade da cultivar ao pseudoperfilhamento, aplicou-se um estresse hídrico, que foi realizado antecipadamente à segunda adubação de cobertura, iniciado aos 45 dias após o plantio. Além disso, devido às características climáticas da região, com temperaturas elevadas e baixa umidade relativa, o estresse não foi realizado sob a suspensão total da irrigação. Assim, durante cinco dias (45-49 DAP), foi utilizada $50 \%$ da lâmina de irrigação recomendada para a fase da cultura, irrigando-se normalmente durante os cinco dias seguintes (50-54 DAP); após isso realizou-se a segunda etapa do estresse, com mais cinco dias (55-59 DAP) de irrigação sob lâmina de $50 \%$ da recomendação. Após o estresse hídrico, retornou-se ao manejo de irrigação indicado para a fase do cultivo, seguindo as recomendações para a cultura.

O manejo de plantas daninhas foi realizado por meio de capinas manuais, realizadas sempre que necessário, de modo que a cultura permanecesse sem interferência. Visando a prevenção e controle de doenças como mancha púrpura, foram realizadas pulverizações com produtos à base de Mancozeb (Manzate $^{\circ}, 2,5 \mathrm{~g} / \mathrm{L}$ ) em intervalos de sete dias. O controle de pragas, como tripes e/ou ácaros foi efetuado mediante pulverizações alternadas em intervalos de quinze dias com produto à base de Clorfernapir (Pirate ${ }^{\odot}, 0,5 \mathrm{~mL} / \mathrm{L}$ ) ou Deltametrina (Decis, $0,3 \mathrm{~mL} / \mathrm{L}$ ).

A irrigação foi suspensa três dias antes da colheita, quando as plantas apresentaram sinais de maturação, caracterizadas pelo amarelecimento e seca de $2 / 3$ da parte aérea. A colheita foi realizada manualmente, pela manhã. As plantas colhidas foram submetidas ao processo de "pré-cura", permanecendo por três dias expostas ao sol, de forma que as folhas de uma planta cobrissem os bulbos de outra, protegendo desta forma da radiação solar direta. Em seguida realizou-se a cura de armazém, onde as plantas permaneceram por um período de 35 dias em local sombreado, seco e arejado. Após o processo de cura, realizou-se a limpeza dos bulbos.

Durante o ciclo foram analisados: Comprimento de plantas em $\mathrm{cm}$ (do nível do solo até a extremidade da folha mais comprida, aos 50 dias após o plantio, em uma amostra de dez plantas); Número de folhas (número médio de folhas fotossinteticamente ativas de dez plantas amostradas aos 50 dias após o plantio); Ciclo (número de dias entre o plantio e a colheita); Estande final (número de plantas colhidas). Após a cura, foram avaliados: Massa média de bulbos em $g$ (relação entre a massa e o número total de bulbos diferenciados após o processo da cura); Plantas com bulbos em \% (bulbos com diferenciação de bulbilhos); Produtividade total de bulbos em $\mathrm{t} / \mathrm{ha}$ (pesagem dos bulbos diferenciados de cada parcela, após o processo completo de cura); Classificação dos bulbos \{conforme portaria $\mathrm{N}^{\circ}$ 242 de 17/09/1992 do MAPA: classe 3 $(>32-37 \mathrm{~mm})$, classe $4(>37-42 \mathrm{~mm})$, classe $5(>42-47 \mathrm{~mm})$, classe $6(>47-$ $56 \mathrm{~mm})$ e classe $7(>56 \mathrm{~mm})\}$. Os bulbos de cada classe foram pesados, e os dados expressos em percentagem de cada classe em relação à produção total de bulbos; Número de bulbilhos por bulbo (relação entre a quantidade de bulbilhos e o número total de bulbos diferenciados); Classificação dos bulbilhos [foram definidos como grandes os bulbilhos retidos na peneira 1 (malha $15 \times 25 \mathrm{~mm}$ ); médios, retidos na peneira 2 (malha 10x20 mm); médios pequenos, retidos na peneira 3 (malha $8 \times 17 \mathrm{~mm}$ ); pequenos, retidos na peneira 4 (malha $5 \times 17 \mathrm{~mm}$ ) e palitos, os que passaram pela peneira 4].

Os dados foram submetidos às análises de variância e regressão. As médias referentes às épocas de plantio foram comparadas pelo teste de Tukey a $5 \%$ de probabilidade, utilizando-se o software Sisvar $^{\circledR}$ v. 5.3 (Ferreira, 2008) e os períodos de vernalização foram submetidos à análise de regressão, obedecendo-se o nível de significância de $5 \%$ de probabilidade pelo teste $\mathrm{F}$, por meio do software Table Curve 2D v5.01 (Jandel Scientific, 1991).

\section{RESULTADOS E DISCUSSÃO}

Houve efeito significativo da interação Épocas de plantio x Períodos de vernalização para comprimento de plantas, número de folhas, ciclo, produção total de bulbos e número de bulbilhos por bulbo. Para o estande final e massa média de bulbos houve efeito apenas das épocas de plantio.

Os períodos de vernalização influenciaram o comprimento de plantas (CP) apenas na terceira época de plantio, com crescimento exponencial com os períodos de vernalização, atingindo o máximo estimado de $49,14 \mathrm{~cm}$ quando o alho foi vernalizado por 64 dias (Figura 1A). Nos plantios em 22/05 e 05/06, o CP foi de 53,03 e $47,46 \mathrm{~cm}$, respectivamente.

Analisando-se as épocas de plantio em cada período de vernalização, observa-se que o plantio em 22/05 propiciou comprimentos superiores ao plantio em $05 / 06$ aos 60 e 65 dias de vernalização (DV), e ao plantio em 23/06 aos 50, 55, 65 e 70 DV (Tabela 1). Resende et al. (2011) verificaram que o plantio em 23/03 proporcionou maior altura de planta, aos $60 \mathrm{DAP}$, do que os plantios em abril e maio para as cultivares Roxo Pérola de Caçador e Quitéria. Diferenças nas médias observadas podem estar relacionadas tanto à época de avaliação, já que no presente trabalho foram realizadas aos 50 DAP, diferindo dos demais, bem como às respostas fisiológicas da cultivar às diferentes condições edafoclimáticas das regiões onde os experimentos foram 
Figura 1. Comprimento de plantas (A), número de folhas (B), ciclo (C) e produtividade total de bulbos (D) de alho nobre submetido a diferentes períodos de vernalização e épocas de plantio (Y1: 22/mai; Y2: 5/jun; Y3: 23/jun) \{plant length (A), number of leaves (B), cycle (C), and bulb yield (D) of noble garlic under different periods of vernalization and planting times (Y1: May 22; Y2: June 5; Y3: June 23)\}. Baraúna, UFERSA, 2012.

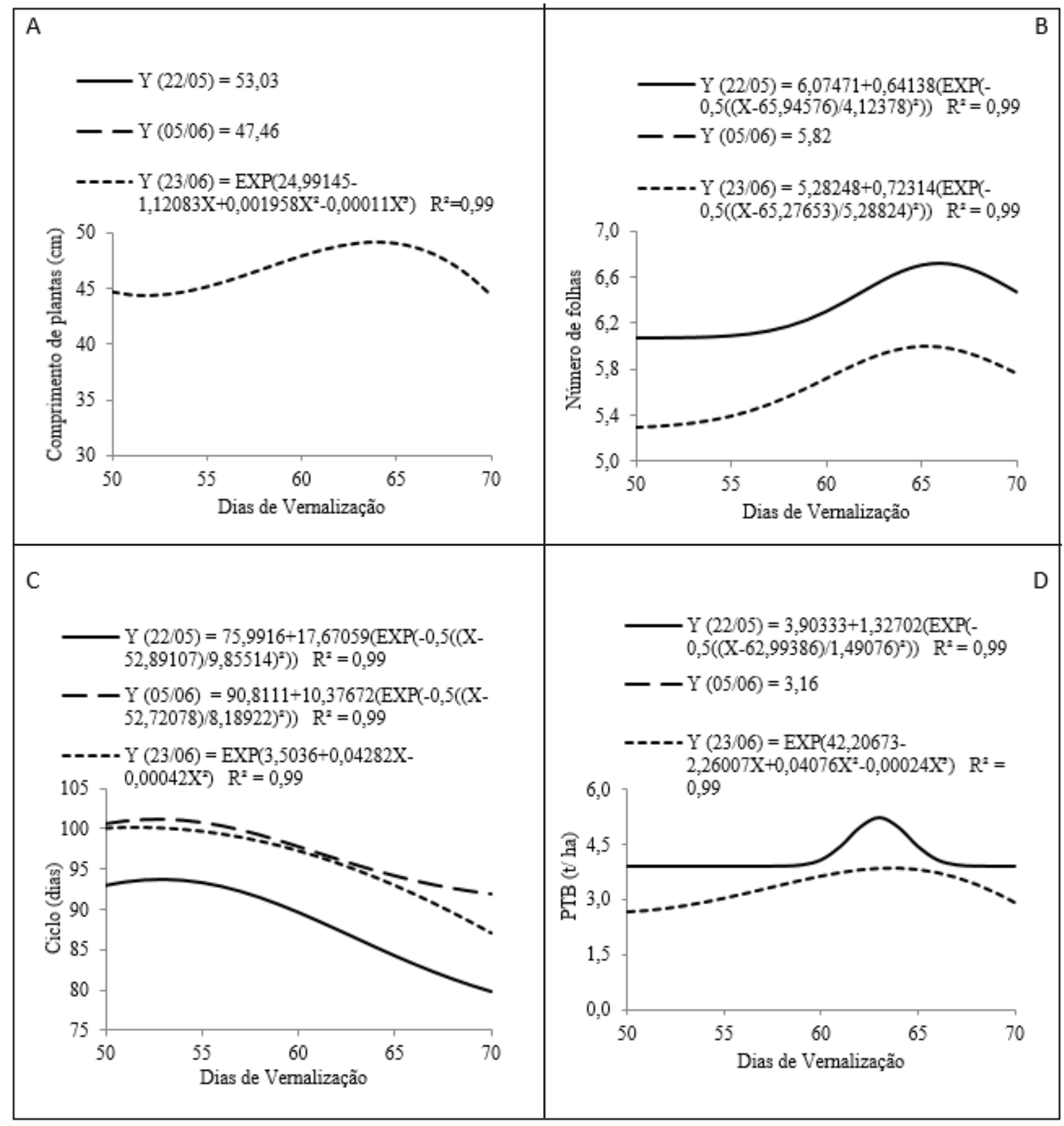

desenvolvidos.

O número de folhas foi afetado pelos períodos de vernalização nos plantios em 22/05 e 23/06, com máximos estimados de 6,7 e 6,0 folhas aos 66 e 65 dias, respectivamente. Para o plantio em 05/06, as plantas permaneceram com média de 5,8 folhas (Figura 1B). Comparando-se as épocas de plantio em cada período de vernalização, verifica-se que, assim como para o comprimento de plantas, o plantio em 22/05 foi superior ao plantio em 05/06 aos $65 \mathrm{DV}$ e ao plantio em 23/06 aos 50, 55, 65 e 70 DV (Tabela 1). O número de folhas e sua disposição no pseudocaule, associados ao comprimento da planta, são resultados do desempenho assimilatório durante certo 
Tabela 1. Comprimento de plantas, número de folhas, ciclo e número de bulbilhos por bulbo de alho nobre submetido a diferentes períodos de vernalização e épocas de plantio (plant length, number of leaves, cycle and number of bulblets per bulb of noble garlic under different vernalization periods and planting times). Baraúna, UFERSA, 2012.

\begin{tabular}{|c|c|c|c|c|c|}
\hline \multirow{2}{*}{ Épocas de plantio } & \multicolumn{5}{|c|}{ Períodos de vernalização } \\
\hline & 50 & 55 & 60 & 65 & 70 \\
\hline & \multicolumn{5}{|c|}{ Altura de plantas (cm) } \\
\hline $22 / \mathrm{mai}$ & $53,20 \mathrm{a}$ & $52,50 \mathrm{a}$ & $52,30 \mathrm{a}$ & $55,20 \mathrm{a}$ & $51,93 \mathrm{a}$ \\
\hline $05 /$ jun & $49,43 \mathrm{ab}$ & $47,83 \mathrm{ab}$ & $47,70 \mathrm{~b}$ & $45,83 \mathrm{~b}$ & $47,50 \mathrm{ab}$ \\
\hline \multirow[t]{2}{*}{ 23/jun } & $44,76 \mathrm{~b}$ & $45,24 \mathrm{~b}$ & $47,87 \mathrm{ab}$ & $49,06 \mathrm{~b}$ & $44,46 \mathrm{~b}$ \\
\hline & \multicolumn{5}{|c|}{ Número de folhas (folhas/planta) } \\
\hline $22 /$ mai & $6,07 \mathrm{a}$ & $6,10 \mathrm{a}$ & $6,30 \mathrm{a}$ & $6,70 \mathrm{a}$ & $6,47 \mathrm{a}$ \\
\hline 05/jun & $5,83 \mathrm{ab}$ & $5,93 \mathrm{ab}$ & $5,63 \mathrm{a}$ & $5,63 \mathrm{~b}$ & $6,07 \mathrm{ab}$ \\
\hline \multirow[t]{2}{*}{$23 /$ jun } & $5,30 \mathrm{~b}$ & $5,38 \mathrm{~b}$ & $5,73 \mathrm{a}$ & $6,00 \mathrm{~b}$ & $5,77 \mathrm{~b}$ \\
\hline & \multicolumn{5}{|c|}{ Ciclo (dias) } \\
\hline $22 /$ mai & $93,00 \mathrm{~b}$ & $93,00 \mathrm{~b}$ & $90,00 \mathrm{c}$ & $84,00 \mathrm{c}$ & $80,00 \mathrm{c}$ \\
\hline $05 /$ jun & $100,67 \mathrm{a}$ & $100,67 \mathrm{a}$ & $98,00 \mathrm{a}$ & $94,00 \mathrm{a}$ & $92,00 \mathrm{a}$ \\
\hline \multirow[t]{2}{*}{ 23/jun } & $100,00 \mathrm{a}$ & $100,00 \mathrm{a}$ & $97,00 \mathrm{~b}$ & $93,00 \mathrm{~b}$ & $87,00 \mathrm{~b}$ \\
\hline & \multicolumn{5}{|c|}{ Número de bulbilhos/bulbo } \\
\hline $22 /$ mai & $7,23 \mathrm{Aa}$ & $7,41 \mathrm{Aa}$ & $6,94 \mathrm{Aa}$ & $7,51 \mathrm{Aa}$ & $6,77 \mathrm{Aa}$ \\
\hline 05/jun & $6,47 \mathrm{Aa}$ & $6,34 \mathrm{Ab}$ & $6,27 \mathrm{ABa}$ & $5,33 \mathrm{Bb}$ & $5,95 \mathrm{ABa}$ \\
\hline 23/jun & 6,33 Aa & $6,27 \mathrm{Ab}$ & 6,63 Aa & 6,67 Aa & $5,95 \mathrm{Aa}$ \\
\hline
\end{tabular}

Médias seguidas pela mesma letra, maiúsculas nas linhas e minúsculas nas colunas, não diferem entre si, pelo teste de Tukey a $5 \%$ de probabilidade (means followed by the same letter, capital in lines and small in columns, do not differ by Tukey test $5 \%$ ).

período de tempo e estão associadas ao manejo empregado na cultura, podendo estar relacionados com a produção final da planta. Pereira \& Souza (2002) verificaram comportamento distinto ao do presente trabalho, com aumento linear do número de folhas com o aumento do tempo de vernalização (0-60 dias). Deve-se considerar que alterações no metabolismo da maioria das hortaliças são causados por temperaturas elevadas durante a fase de campo, bem como pelo uso da técnica da vernalização no cultivo do alho. Desse modo, a interação entre os referidos fatores, para a pesquisa em questão, explica o comportamento diferenciado ao observado pelos autores em Lavras-MG, já que as regiões possuem condições de clima distintos. Portanto, é possível que os autores observassem reduções no número de folhas, se utilizassem também períodos de vernalização superiores a 60 dias.

O ciclo vegetativo decresceu com o aumento dos períodos de vernalização, em todas as épocas de plantio, com máximos estimados de 93, 101 e 100 dias com 52, 52 e 51 dias de vernalização e mínimos de 79, 91, 86 dias quando vernalizado por 70 dias, nos plantios em 22/05, 05/06 e 23/06, respectivamente (Figura 1C). O menor ciclo vegetativo da cultura em todos os períodos de vernalização foi observado no plantio em $22 / 05$. No plantio em $05 / 06$, observou-se maior ciclo, não diferindo do plantio em 23/06 apenas com 50 e 55 dias de vernalização (Tabela 1). As reduções no ciclo, observadas com o aumento do período de vernalização, estão em acordo com observações feitas em outras regiões de cultivo do alho vernalizado; no entanto, devido às menores latitude e altitude, associados a temperaturas médias mais elevadas na área experimental, para todas as épocas de plantio, os valores observados estão abaixo dos relatados por outros autores. Reghin \& Kimoto (1998) observaram que aumentando o tempo de vernalização de 30 para 60 dias, houve redução no ciclo de 140 para 119 dias. Resende et al. (2011), avaliando três épocas de plantio (23/03, 23/04 e 23/05) em Guarapuava-PR, afirmam que o plantio mais tardio proporcionou ciclo mais curto para a cultivar Roxo Pérola de Caçador. Por outro lado, Pereira \& Souza (2002) relatam uma média de 162 dias de ciclo para a cultivar Roxo Pérola de Caçador em três épocas de plantio (01/03, 31/03 e 01/05), em Lavras-MG, com reduções de 59 dias com o aumento do período de 0 a 60 dias de vernalização.

Levando-se em consideração uma população de $350 \mathrm{mil}$ plantas/ha, observa-se que para todas as épocas de plantio, o estande final, plantas sobreviventes colhidas ao final do ciclo, foi acima de $85 \%$, o que pode ser, quando associado à percentagem de bulbos com diferenciação de bulbilhos, um indicativo de sucesso do processo de vernalização para regiões com as condições semelhantes às do presente experimento. O plantio em 22/05 resultou em maior número de plantas colhidas $(93,83 \%=$ 328.395 plantas/ha), que foi superior ao plantio em $05 / 06(85,68 \%=299.876$ plantas/ha), ambos não diferindo do plantio em $23 / 06(90,86 \%=318.024$ plantas/ha) (Tabela 2). Estes dados corroboram, em parte, com Soares (2015) que trabalhou com cultivares de alho comum em Governador Dix-sept Rosado-RN, município também pertencente à região de Mossoró, e observou estande 
Tabela 2. Estande final (EF) e massa média de bulbos (MMB) de alho nobre submetido a diferentes períodos de vernalização e épocas de plantio \{final stand (EF) and average bulb weight (MMB) of noble garlic under different vernalization periods and planting times\}. Baraúna, UFERSA, 2012.

\begin{tabular}{lcc}
\hline Época & EF (\%) (plantas/ha) & MMB (g) \\
\hline $22 /$ mai & $93,83(328.395) \mathrm{a}$ & $12,35 \mathrm{a}$ \\
$05 /$ jun & $85,68(299.876) \mathrm{b}$ & $10,54 \mathrm{~b}$ \\
$23 /$ jun & $90,86(318.024) \mathrm{ab}$ & $10,32 \mathrm{~b}$ \\
\hline
\end{tabular}

Médias seguidas pela mesma letra nas colunas, não diferem entre si, pelo teste de Tukey a $5 \%$ de probabilidade (means followed by the same letter, in the columns, do not differ by Tukey test 5\%).

final variando entre 82,87 e $100 \%$, indicando a possibilidade do cultivo de alho na região da pesquisa.

Assim como o EF, a massa média de bulbos (MMB) foi influenciada apenas pelas épocas de plantio. Verifica-se que assim como para o estande final, o plantio em 22/05 foi o que proporcionou maior MMB, com média de 12,35 g (Tabela 2). O fato de ter proporcionado maior MMB, mesmo com menor ciclo vegetativo, é consequência do maior vigor de plantas, mensurado pelo número de folhas e comprimento de plantas durante a referida época. Entretanto, devido à acentuada redução no ciclo da cultivar, consequência da prática de vernalização, quando comparada a outras regiões, as plantas não dispuseram de tempo suficiente para alcançar seu pleno desenvolvimento vegetativo, consequentemente, a massa média de bulbos foi inferior à observada por outros autores. Resende et al. (2001) afirmam que para a cultivar Quitéria não houve diferença entre a massa média de bulbos comerciais quando utilizou-se a frigorificação por 40 e 60 dias, com médias variando entre 12,7 e 14,2 g/bulbo. Souza \& Macêdo (2004) observaram massa média de bulbos comerciais de cultivares de alho vernalizado variando entre 21,4 e 39,9 g.

Para a percentagem de plantas com formação de bulbos, observou-se diferenciação de bulbilhos em todas as plantas colhidas, para todos os períodos de vernalização e épocas de plantio. Pode-se afirmar, portanto, que os tratamentos empregados supriram a exigência da cultivar em fotoperíodo longo e temperatura baixa para ocorrer a diferenciação de bulbilhos e formação de bulbos, nas condições de Baraúna-RN. Resende et al. (2001) afirmam não haver diferenciação quando não se realizou a vernalização ou quando o período utilizado foi de 20 dias, para a cultivar Quitéria, nas condições de Lavras-MG, resultados distintos, possivelmente devido a diferenças entre genótipo e ambiente em relação aos utilizados na presente pesquisa.

A produtividade total de bulbos (PTB) variou em função dos períodos de vernalização em cada época de plantio. Para o plantio em 22/05, a PTB estimada foi de 3,90 t/ha até aproximadamente 60 dias de vernalização, alcançando máxima estimada de 5,20 t/ha aos 63 dias de vernalização, decrescendo posteriormente até $2,93 \mathrm{t} / \mathrm{ha}$ quando vernalizado por 70 dias. No plantio em 05/06 não foram observadas diferenças significativas, com PTB média de 3,16 t/ha. Para o plantio em 23/06, com 50 dias de vernalização, houve PTB de 2,68 t/ha, até máximo estimado de 3,85 t/ha com 63 dias de vernalização, decrescendo até os 70 dias, com média estimada em 2,93 t/ha (Figura 1D).

Avaliando-se o efeito das épocas de plantio em cada período de vernalização, o plantio em 22/05 se mostrou mais adequado para o cultivo do alho, em todos os períodos de vernalização, devido às temperaturas mais amenas observadas em campo durante essa época, resultando em maior PTB, apesar de não diferir do plantio em $05 / 06$ aos 50 e 55 dias, e do plantio em 23/06, aos 60 e 65 dias de vernalização (Tabela 3). A produtividade média foi baixa quando comparada à média nacional $(10,6 \mathrm{t} / \mathrm{ha})$ desse mesmo ano (IBGE, 2013). Reghin \& Kimoto (1998) afirmam que fatores como época de plantio, tratamento pré-plantio e as condições ambientais posteriores ao tratamento têm influência sobre a produção final da planta. Além disso, características genéticas inerentes a cada cultivar também devem ser considerados. Este fato pode ser comprovado por Resende et al. (2011), quando afirmam que a produção de bulbos com maior padrão comercial foi obtida nas duas primeiras épocas (março e abril) para a cultivar Quitéria e na segunda época para a cultivar Caçador. Além disso, os autores afirmam que o período de 40 dias de vernalização foi o que permitiu melhor adaptação de ambas as cultivares às condições de fotoperíodo e temperatura, proporcionando um desenvolvimento vegetativo e produtivo satisfatório na região de Guarapuava-PR. Souza \& Macêdo (2004) obtiveram PTB variando entre 8,58 e $18,42 \mathrm{t} / \mathrm{ha}$ para cultivares de alho vernalizadas por 50 dias em Lavras-MG.

A combinação entre o plantio em 22/05 e a vernalização do alho-semente por 65 dias, destaca-se dos demais tratamentos, pois além de proporcionar a maior PTB $(4,44 \mathrm{t} / \mathrm{ha})$, proporcionou maior percentual de bulbos comerciais, com médias de $48,29,12,39$ e $3,79 \%$ nas classes 3, 4 e 5, respectivamente (Tabela 3). Por outro lado, quando utilizou-se 50 dias de vernalização e plantio em 23/06, obteve-se, além da menor PTB $(2,68 \mathrm{t} /$ ha), a maior percentagem de bulbos classificados como refugo $(74,92 \%)$, com diâmetro médio abaixo de $32 \mathrm{~mm}$. Estes resultados estão abaixo dos obtidos em regiões tradicionalmente produtoras de alho, entretanto, por meio deles pode-se afirmar que o processo de vernalização adapta-se às condições em que o experimento foi realizado.

Estes resultados estão de acordo com o obtido por Reghin \& Kimoto (1998) que afirmam que nem sempre os tratamentos que promovem maiores adiantamentos na bulbificação e, consequentemente, reduzem o ciclo, comprometem a produção e a qualidade comercial do produto; em contraposição, Silva et al. (2000) afirmam que à medida que se aumentou o tempo de frigorificação (040 dias), a produção não comercial, com bulbos pequenos, miúdos e superbrotados, também aumentou indicando que a 
Tabela 3. Produtividade total de bulbos (PTB) e distribuição de bulbos em classes de tamanho de alho nobre submetido a diferentes períodos de vernalização (PV) e épocas de plantio (total yield of bulbs and distribution of noble garlic bulbs in classes submitted to different vernalization periods and planting times). Baraúna, UFERSA, 2012.

\begin{tabular}{|c|c|c|c|c|c|c|}
\hline \multirow[b]{2}{*}{ PV } & \multirow[b]{2}{*}{$\begin{array}{l}\text { Época de } \\
\text { plantio }\end{array}$} & \multirow[b]{2}{*}{$\begin{array}{l}\text { PTB } \\
(\mathrm{t} / \mathrm{ha})\end{array}$} & \multicolumn{4}{|c|}{ Classificação } \\
\hline & & & $\begin{array}{c}\text { Refugo } \\
(<32 \mathrm{~mm})\end{array}$ & $\begin{array}{c}\text { Classe } 3 \\
(>32-37 \mathrm{~mm})\end{array}$ & $\begin{array}{c}\text { Classe } 4 \\
(>37-42 \mathrm{~mm})\end{array}$ & $\begin{array}{c}\text { Classe } 5 \\
(>42-47 \mathrm{~mm})\end{array}$ \\
\hline \multirow{3}{*}{50} & $22 /$ mai & $3,91 \mathrm{a}$ & 45,87 & 48,85 & 3,91 & 1,37 \\
\hline & 05/jun & $3,47 \mathrm{a}$ & 61,85 & 35,85 & 2,30 & 0,00 \\
\hline & $23 /$ jun & $2,68 \mathrm{~b}$ & 74,92 & 22,26 & 2,82 & 0,00 \\
\hline \multirow{3}{*}{55} & $22 /$ mai & $3,93 \mathrm{a}$ & 39,96 & 50,62 & 9,42 & 0,00 \\
\hline & 05/jun & $3,37 \mathrm{ab}$ & 63,27 & 35,28 & 1,45 & 0,00 \\
\hline & $23 /$ jun & $3,05 \mathrm{~b}$ & 79,35 & 18,13 & 2,52 & 0,00 \\
\hline \multirow{3}{*}{60} & $22 /$ mai & $4,08 \mathrm{a}$ & 46,80 & 47,08 & 6,12 & 0,00 \\
\hline & 05/jun & $3,03 \mathrm{~b}$ & 72,08 & 24,35 & 3,57 & 0,00 \\
\hline & $23 /$ jun & $3,64 \mathrm{ab}$ & 55,78 & 38,83 & 5,39 & 0,00 \\
\hline \multirow{3}{*}{65} & $22 / \mathrm{mai}$ & $4,44 \mathrm{a}$ & 35,53 & 48,29 & 12,39 & 3,79 \\
\hline & 05/jun & $2,89 \mathrm{~b}$ & 73,48 & 24,06 & 2,46 & 0,00 \\
\hline & $23 /$ jun & $3,82 \mathrm{a}$ & 55,68 & 37,43 & 4,57 & 2,32 \\
\hline \multirow{3}{*}{70} & $22 /$ mai & $3,87 \mathrm{a}$ & 49,37 & 47,57 & 3,06 & 0,00 \\
\hline & 05/jun & $3,03 \mathrm{~b}$ & 71,50 & 27,25 & 1,25 & 0,00 \\
\hline & $23 /$ jun & $2,93 \mathrm{~b}$ & 73,93 & 26,07 & 0,00 & 0,00 \\
\hline
\end{tabular}

Médias seguidas pela mesma letra, comparam épocas de plantio em cada período de vernalização, não diferem entre si, pelo teste de Tukey a $5 \%$ de probabilidade (means followed by the same letter, comparing planting times in each period of vernalization, do not differ by Tukey test $5 \%$ ).

frigorificação dos bulbos foi prejudicial para as cultivares Gravatá, Gigante de Lavínia, Gigante Roxo, Gigante Curitibanos e Juréia em Lavras-MG.

Em nenhum dos tratamentos empregados observou-se pseudoperfilhamento ou superbrotamento de plantas. Tal observação entra em contradição com frequentes citações da ocorrência de superbrotamento em alho vernalizado (Resende et al., 2001; Macêdo et al., 2006; Souza \& Macêdo, 2009). Mann \& Minges (1958) apud Souza \& Macêdo (2009) relatam que a possibilidade do surgimento do superbrotamento se deve à estreita relação entre baixas temperaturas e a sensibilidade da cultivar. No entanto, além das condições de temperaturas mais elevadas, com média diária acima de $25^{\circ} \mathrm{C}$ durante todo o ciclo, na presente pesquisa também se realizou o estresse hídrico, citado por Macêdo et al. (2006), na fase anterior à diferenciação dos bulbilhos, visando à redução do superbrotamento.

Não foi encontrada curva resposta ajustada para o comportamento do número de bulbilhos/bulbo (NBB) em função dos períodos de vernalização. Para os plantios em 22/05 e 23/06, não foram observadas diferenças significativas entre os períodos de vernalização, com médias variando entre 6,77 e 7,51 (22/05), e entre 5,95 e 6,67 bulbilhos/ bulbo $(23 / 06)$ (Tabela 1). No plantio em $05 / 06$ os períodos de 50 e 55 dias de vernalização proporcionaram maior NBB comparado com 65 dias de vernalização, com médias de 6,47 e 6,34 bulbilhos/bulbo, respectivamente.

Comparando as épocas de plantio em cada período de vernalização, foram observadas diferenças apenas quando da utilização de 55 e 65 dias de vernalização com máximo de 7,41 no plantio em 22/05, com $55 \mathrm{DV}$, e de 7,51 e 6,67, nos plantios em 22/05 e 23/06, com 65 DV, respectivamente. A portaria $\mathrm{N}^{\circ} 242 / 92$, do Ministério da Agricultura, prevê que, para pertencer ao grupo nobre, o alho deve possuir, entre outras características, no máximo 20 bulbilhos/bulbo. O mercado consumidor de alho prefere bulbos de tamanho maior e com pequeno número de bulbilhos/bulbo, fato importante para a comercialização, quando bulbos com estas características alcançam as cotações mais elevadas. Resende et al. (2001) não verificaram diferenças quanto ao NBB quando os bulbos foram frigorificados por 40 e 60 dias, e que não houve diferenciação de bulbilhos, quando utilizou-se a vernalização por 20 dias ou menos. Médias variando entre 8 e 13 bulbilhos/bulbo foram observadas por Souza \& Macêdo (2004), utilizando 50 dias de vernalização. Assim como para o NBB, não observou-se um comportamento padrão de distribuição dos bulbilhos por classe/peneira em função dos períodos de vernalização ou épocas de plantio; entretanto, vale ressaltar que para todos os tratamentos, a maior parte dos bulbilhos ficou retida na peneira 3 , seguido das peneiras 4,2 e 1, com médias de 50, 36,8, 13 e $0,2 \%$, respectivamente.

Todos os tratamentos empregados possibilitaram a diferenciação celular e formação de bulbos de alho com boa qualidade para o consumo, o que demonstra a eficiência da prática da vernalização para regiões de clima semiárido. Deve-se ainda enfatizar 
que, independente das produtividades obtidas, a vernalização possibilita a adaptação de cultivares de alho mais exigentes em fotoperíodo e temperatura e a expansão do cultivo para novas áreas, como a região da pesquisa ou regiões com condições de clima semelhantes às observadas durante a fase de campo. Além disso, as produtividades podem ser aperfeiçoadas com aprimoramento do sistema de produção, tais como testes de novas épocas de plantio; avaliação de novas cultivares de alho nobre; avaliação de cultivares livres de vírus; manejo de adubação, irrigação, densidade de plantio entre outros.

Por meio dos resultados obtidos, constatou-se que o plantio em 22/05 proporcionou comprimento de plantas, número de folhas, estande final e massa média de bulbos maiores que os demais; o ciclo decresceu com o aumento do tempo de vernalização; houve formação de bulbos com diferenciação de bulbilhos em todos os tratamentos sem, entretanto, haver ocorrência de plantas com superbrotamento; a produtividade total de bulbos aumentou com o tempo de vernalização de até 63 dias nos plantios em $22 / 05$ e $23 / 06$, com médias de 5,20 e $3,85 \mathrm{t} / \mathrm{ha}$; maior número de bulbilhos por bulbo e maior percentual de bulbos comerciais foi obtido com a combinação do plantio em 22/05 e 65 dias de vernalização, sendo estes distribuídos nas classes 3, 4 e 5. Esses resultados evidenciam ser possível o cultivo de alho nobre na região de Mossoró-RN utilizando o processo de frigorificação do alho-planta.

\section{AGRADECIMENTOS}

Os autores agradecem ao Conselho
Nacional de Desenvolvimento Científico e Tecnológico (CNPq) pelo apoio financeiro concedido para a realização do projeto de pesquisa, bem como à Marx Wilder Fernandes, diretor da Fazenda Santa Luzia, pelo apoio logístico.

\section{REFERÊNCIAS}

EMBRAPA. 2013. Sistema brasileiro de classificação de solos. Rio de Janeiro: Embrapa Solos. 353p.

FERREIRA, DF. 2008. SISVAR: um programa para análises e ensino de estatística. Revista Symposium 6: 36-41.

FIORESE, EJ; VIECELLI, CA. 2009. Tratamento termoterápico sobre seis cultivares de alho. Cultivando o saber 2: 26-31.

IBGE - Instituto Brasileiro de Geografia e Estatística. 2013. Levantamento Sistemático da Produção Agrícola 26: 1-86.

JANDEL SCIENTIFIC. 1991. Table Curve: curve fitting software. Corte Madera, CA: 280p.

MACÊDO, FS; SEDOGUCHI, ET; SOUZA, RJ; CARVALHO, JG. 2011. Produtividade de alho vernalizado em função de fontes e doses de fósforo. Ciência Rural 41: 379-383.

MACÊDO, FS; SOUZA, RJ; CARVALHO, JG; SANTOS, BR; LEITE, LVR. 2009. Produtividade de alho vernalizado em função de doses de nitrogênio e molibdênio. Bragantia 68: 657-663.

MACÊDO, FS; SOUZA, RJ; PEREIRA, GM. 2006. Controle de superbrotamento e produtividade de alho vernalizado sob estresse hídrico. Pesquisa Agropecuária Brasileira 41: 629-635.

OLIVEIRA, CM; SOUZA, RJ; YURI, JE; MOTA, JH; RESENDE, GM. 2004. Época de colheita e potencial de armazenamento em cultivares de alho. Horticultura Brasileira 22: 804-807.

PEREIRA，AJ; SOUZA，RJ. 2002. Desenvolvimento e produção de alho submetido a diferentes períodos de vernalização e épocas de plantio. Horticultura Brasileira 20: 565566.
REGHIN, MY; KIMOTO, T. 1998. Dormência, vernalização e produção de alho após diferentes tratamentos de frigorificação de bulbilhos-semente. Horticultura Brasileira 16: 73-79.

RESENDE, GM; SOUZA, RJ; SAGGIN JÚNIOR, OJ; FLORI, JE. 2001. Produtividade e qualidade de bulbos de alho em diferentes doses de paclobutrazol e períodos de frigorificação. Ciência e Agrotecnologia 25: 1343-1350.

RESENDE, JTV; MORALES, RGF; RESENDE, FV; FARIA, MV; SOUZA, RJ; MARCHESE, A. 2011. Garlic vernalization and planting dates in Guarapuava. Horticultura Brasileira 29: 193-198.

RESENDE, JTV; MORALES, RGF; ZANIN, DS; RESENDE, FV; PAULA, JT; DIAS, DM; GALVÃO, AG. 2013. Caracterização morfológica, produtividade e rendimento comercial de cultivares de alho. Horticultura Brasileira 31: 157-162.

SILVA, EC; SOUZA, RJ; SANTOS, VS. 2000. Efeitos do tempo de frigorificação em cultivares de alho (Allium sativum) provenientes de cultura de meristemas. Ciência e Agrotecnologia 24: 939-946.

SOARES, AM; NEGREIROS, MZ; RESENDE, FV; LOPES, WAR; MEDEIROS, JF; GRANGEIRO, LC. 2015. Avaliação de cultivares de alho no município de Governador Dix-sept Rosado-RN, Brasil. RevistaAgro@ mbiental 9: 423-430.

SOUZA, RJ; MACÊDO, FS. 2004. Vernalização de cultivares de alho nobre na região de Lavras. Horticultura Brasileira 22: 651-654.

SOUZA, RJ; MACÊDO, FS. 2009. Cultura do alho: tecnologias modernas de produção. Lavras: UFLA. 181p.

SOUZA, RJ; MACÊDO, FS; CARVALHO, JG; SANTOS, BR; LEITE, LVR. 2011. Absorção de nutrientes em alho vernalizado proveniente de cultura de meristemas cultivado sob doses de nitrogênio. Horticultura Brasileira 29: 498-503.

TRANI, PE; CAMARGO, MS; FOLTRAN, DE; HIROCE, R; ARRUDA, FB; SAWAZAKI, HE. 2008. Produtividade e pseudoperfilhamento do alho influenciados pelo nitrogênio, potássio e cobertura morta. Horticultura Brasileira 26: 330-334. 